\title{
Reject or revive? The crisis of cultural taxonomy in the European Upper Palaeolithic and beyond
}

\author{
Natasha Reynolds ${ }^{1, *} \&$ Felix Riede ${ }^{2}$
}

We begin this response by thanking Antiquity for hosting this debate on the current crisis in European Upper Palaeolithic cultural taxonomy, and by thanking the three commentators for their perspectives (Marwick 2019; Scerri 2019; Shea 2019). We note that our critique of the motley crew of contemporary cultural taxonomies and the plethora of practices producing them is positively received by all of the commentators. Importantly, Ben Marwick, Eleanor Scerri and John Shea further note that these issues are of much broader geographic concern, extending to Palaeolithic cultural taxonomies in Africa and North America. While our primary expertise and hence the focus of our original contribution lies with the European Upper Palaeolithic, classification issues evidently also beset less well-published records such as the South American Palaeoindian period (Araujo 2015), the Mesolithic of Northern Europe (Friman 1996) and, most probably, many other regions where European approaches to lithic classification have been applied. The issues that we raise appear as widespread as they are urgent.

We further note the strong support given to our call for improved data standards and data sharing. Both Scerri and Marwick rightly flag up structural issues of intellectual ownership and power in the discipline. The firmly entrenched notion that excavators or analysts own data or, even worse, actual material or the right to access it, remains widespread and is likely to change only slowly. Although it remains true that, as Scerri points out, data are a form of hard 'currency' for many researchers, in other fields, as Marwick observes, data sharing is insisted upon, creating a level playing field for those confronted with a highly competitive job market. It should also be noted that we are not recommending that all data are shared as soon as they are collected and before the researcher has had the chance to analyse and publish. Rather, we advocate that data are shared alongside any publications that rely upon them, and that all research projects have a strategy for storing and sharing their data (cf. the datamanagement plans required as part of projects funded by Horizon 2020). Fundamentally, as Marwick discusses, solving the problem of the availability of data about our shared human past is not just important for doing better archaeology, but is also at heart a question

1 UMR 5199 PACEA, Université de Bordeaux, Bâtiment B8, Allée Geoffroy Saint Hilaire, CS 50023, 33615 PESSAC CEDEX, France

2 Department of Archaeology and Heritage Studies, Aarhus University, Moesgård Allé 20, Højbjerg 8270, Denmark

* Author for correspondence (Email: natasha.reynolds@u-bordeaux.fr)

(C) Antiquity Publications Ltd, 2019. This is an Open Access article, distributed under the terms of the Creative Commons Attribution licence (http://creativecommons.org/licenses/by/4.0/), which permits unrestricted re-use, distribution, and reproduction in any medium, provided the original work is properly cited.

ANTIQUITY 93371 (2019): 1368-1370

https://doi.org/10.15184/aqy.2019.156 
of equitability and scientific fairness. Given the pervasive structural inequalities in access to the archaeological record, those of us who have the privilege of researching the past have a responsibility to share fully the data collected.

Like Scerri, we also hope that funding agencies and employers will be supportive of basic, blue-skies archaeological research that tackles both empirical and conceptual issues. Arguably, it has been an accretionist, risk-averse approach to traditional cultural taxonomies that has largely created the current situation. Marwick's very welcome situating of the problem within the wider context of the philosophy of science suggests that significant breakthroughs may be forthcoming if we can change our approach, although we cannot expect overnight results. Following Shea's pragmatic suggestion, however, we would also urge reform-minded colleagues to blaze the trail where they can; they will not only most likely enjoy increased impact (cf. McKiernan et al. 2016), but also contribute to changing practice by example.

Those of us who teach can multiply our agency in this matter by reaching out to the coming generations of professionals. Guidelines for best practice in open science are now available (Cook et al. 2018) and, when coupled with critical thinking concerning disciplinary history and methods, we have a powerful cocktail for change. Those among us who sit on assessment committees, review panels and editorial boards also play an important role in changing the standards of scholarly practice within the discipline, as noted by Marwick.

What might such a new practice look like? Shea and, perhaps to a lesser extent, Scerri promote the radical position of abandoning the now well-known NASTIES-Shea's (2014) NAmed Stone Tool IndustriES — of traditional taxonomies. As much as we see the flaws in contemporary taxonomies as fundamental, we are hesitant to reject cultural taxonomy outright. There is structure in the archaeological record, and abandoning taxonomies altogether would limit, we fear, the types of questions that we can ask and the resolution at which we can address culture change. This is especially the case for the European Upper Palaeolithic, where technotypological patterning in the record, in space and time, is clearer than it is elsewhere. With Scerri (2019: 1364), we plead for describing lithic "variation on its own terms", that is, from the bottom up and in ways that allow objects, measurements and interpretations to be followed and replicated; as these data are aggregated across assemblages, structure inevitably emerges. Taxonomic descriptions of this structure do have their uses, not least for communication.

Naturally, we agree entirely with Shea's point that archaeologists should define their own research goals, but the absence of a robust cultural taxonomy in the Upper Palaeolithic makes it much harder than it should be: we are currently burdened with an unreliable framework for describing the record. This makes it extremely difficult to design and conduct large-scale investigations of variation and change. We need better understanding of the cultural taxonomy of the Upper Palaeolithic not just to enable comparison with results from other fields, but also so that we can formulate better archaeological questions. That said, Scerri is right to observe that our failure to create more robust datasets has led to the devaluation of archaeology within interdisciplinary studies of prehistory: our present shortcomings have repercussions for the status of our field as a whole.

Rather than rejecting cultural taxonomy, we would prefer to see renewed attention and debate well beyond this forum. We also hope to see rapid changes in archaeological practice to provide more shared data and methodological descriptions that can inform this debate. In 
their comments, both Marwick and Scerri note the many new tools-for data acquisition, analysis and sharing - that have become available in recent years. These developments are encouraging. The last time Stone Age taxonomies were debated in the pages of Antiquity (see Neeley \& Barton 1994, and the responses reviewed by Barton \& Neeley 1996), no resolution was apparent, and despite the wide citation of this debate within the literature, it appears to have had little concrete impact on classification practice. By taking advantage of the new means of open science, however, we will not be restricted to arguing our points based on the limited evidence traditionally available, but can bring a transformative dose of data to bear on this most longstanding of archaeological problems.

\section{Acknowledgements}

We are very grateful to the respondants, Ben Marwick, Eleanor Scerri and John Shea, for their perceptive commentary. N.R. thanks the European Union's Horizon 2020 research and innovation programme under Marie Skłodowska-Curie grant agreement 747400; F.R. thanks the Independent Research Fund Denmark for grant 6107-00059B and the European Research Council (Consolidator Grant agreement 817564 under the Horizon 2020 research and innovation programme).

\section{References}

Araujo, A.G.M. 2015. On vastness and variability: cultural transmission, historicity, and the Paleoindian record in Eastern South America. Anais da Academia Brasileira de Ciências 87: 1239-58. https://doi.org/10.1590/00013765201520140219

Barton, C.M. \& M.P. Neeley. 1996. Phantom cultures of the Levantine Epipaleolithic. Antiquity 70: 139-47. https://doi.org/10.1017/S0003598X00082995

CoOK, K., C. Çakirlar, T. Goddard, R.C. DeMuth \& J. Wells. 2018. Teaching open science: published data and digital literacy in archaeology classrooms. Advances in Archaeological Practice 6: 144-56. https://doi.org/10.1017/aap.2018.5

Friman, B. 1996. Does the Kongemose Culture exist? About the concept of culture. Archaeologia Polona 34: 143-63.

Marwick, B. 2019. Galisonian logic devices and data availability: revitalising Upper Palaeolithic cultural taxonomies. Antiquity 93: 1365-67. https://doi.org/10.15184/aqy.2019.131
McKiernan, E.C., P.E. Bourne, C.T. Brown, S. Buck, A. Kenall, J. Lin, D. McDougall, B.A. Nosek, K. Ram, C.K. Soderberg, J.R. Spies, K. Thaney, A. Updegrove, K.H. Woo \& T. Yarkoni. 2016. How open science helps researchers succeed. eLife 5: e16800. https://doi.org/10.7554/eLife.16800

Neeley, M.P. \& C.M. Barton. 1994. A new approach to interpreting Late Pleistocene microlith industries in Southwest Asia. Antiquity 68: 275-88. https://doi.org/10.1017/S0003598X00046585

SCERri, E.M.L. 2019. Cultural taxonomy for the European Upper Palaeolithic: a wide-ranging problem. Antiquity 93: 1362-64. https://doi.org/10.15184/aqy.2019.135

SHEA, J.J. 2014. Sink the Mousterian? Named stone tool industries (NASTIES) as obstacles to investigating hominin evolutionary relationships in the Later Middle Paleolithic Levant. Quaternary International 350: 169-79. https://doi.org/10.1016/j.quaint.2014.01.024

- 2019. European Upper Palaeolithic cultural taxa: better off without them? Antiquity 93: 1359-61. https://doi.org/10.15184/aqy.2019.117 